\title{
Computation of the Stability and Complexity about Triopoly Price Game Model with Delay Decision
}

\author{
Yuling Wang, ${ }^{1}$ Shubing Guo, ${ }^{2}$ and Shide Duan ${ }^{1}$ \\ ${ }^{1}$ School of Economics, South-Central University for Nationalities, Wuhan, China \\ ${ }^{2}$ College of Management and Economics, Tianjin University, Tianjin 300072, China \\ Correspondence should be addressed to Shubing Guo; sbguo20160831@126.com
}

Received 1 January 2017; Accepted 21 February 2017; Published 10 April 2017

Academic Editor: Kaliyaperumal Nakkeeran

Copyright (c) 2017 Yuling Wang et al. This is an open access article distributed under the Creative Commons Attribution License, which permits unrestricted use, distribution, and reproduction in any medium, provided the original work is properly cited.

\begin{abstract}
We develop the price game model based on the entropy theory and chaos theory, considering the three enterprises are bounded rationality and using the cost function under the resource constraints; that is, the yield increase will bring increased costs. The enterprises of new model adopt the delay decision with the delay parameters $\tau_{1}$ and $\tau_{2}$, respectively. According to the change of delay parameters $\tau_{1}$ and $\tau_{2}$, the bifurcation, stability, and chaos of the system are discussed, and the change of entropy when the system is far away from equilibrium is considered. Prices and profits are found to lose stability and the evolution of the system tends to the equilibrium state of maximum entropy. And it has a big fluctuation with the increase of $\tau_{1}$ and $\tau_{2}$. In the end, the chaos is controlled effectively. The entropy of the system decreases, and the interior reverts to order. The results of this study are of great significance for avoiding the chaos when the enterprises make price decisions.
\end{abstract}

\section{Introduction}

The oligopoly is a universal market state between perfect competition and complete monopoly. Game theory, entropy theory, and nonlinear dynamics provide new impetus for oligopoly theory. There are a lot of oligopolies in the market, such as China Mobile, China Unicom, and China Telecom, forming a complex system with increasing entropy. These oligopoly enterprises constantly carry on the price game in order to maximize the benefits. Many scholars have studied the content of oligopoly game from different perspectives, such as entropy theory, chaos, and game theory. Zhang et al. [1] built a Bertrand repeated game model with linear demand function and studied its system complexity. $\mathrm{Xu}$ and $\mathrm{Ma}$ [2] investigated the dynamic model of a Bertrand game with delay in insurance market. They discussed the existence of the Nash equilibrium point of the game and researched the stability of the system. Sun and Ma [3] considered a two-player quantum game in the presence of a thermal decoherence modeled with the method of a rigorous Davies. It shows how the energy dissipation and pure decoherence make changes on the payoffs of the players in the game. Dajka et al. [4] studied the complex dynamics of a nonlinear model on the basis of Bertrand game in Chinese cold rolled steel market. Fanti et al. [5] analyzed the dynamics of a Bertrand duopoly with products which become divided. The results showed that an increase in either the degree of substitutability or complementarity between products of different varieties was the reason of complexity in a competition game. Xiangyu and Xiaoyong [6] used the information theory and entropy theory to build the models to measure the entropy of the four market structures which are perfect competition, monopolistic competition, oligopoly, and complete monopoly and compare the entropy of the four market structures. Naimzada and Tramontana [7] considered a Cournot-Bertrand duopoly model based on linear demand and cost functions with product differentiation. Li and $\mathrm{Ma}[8]$ considered the R\&D input competition model in oligopoly market on the basis of that the players are heterogeneous, bounded rational, and adaptive adjustment. Fan et al. [9] investigated two types of players and concluded the output duopoly game with heterogeneous players. They studied the influence of players' different behavior on the dynamics of game. Yali [10] built a duopoly game model and investigated its stability with bounded rationality strategy and state delay. Gao et al. [11] discussed equilibrium stability of a nonlinear Cournot 
duopoly game, where one player can evaluate its opponent's output in the future in light of straightforward extrapolative foresight. Peng et al. [12] analyzed a dynamic of triopoly Bertrand repeated model with the zero marginal cost. Bischi and Naimzada [13] concluded the dynamical characteristics of bounded rationality duopoly game. Ma and $\mathrm{Tu}$ [14] carried out the corresponding extension of the complex dynamics to macroeconomic model with time delays considering the macroeconomic model of money supply. Ma and Wang [15] considered a closed-loop supply chain with product recovery, which is composed of one manufacturer and one retailer. The situation may lead to complicated dynamic phenomena such as bifurcation and chaos. That is to say, the entropy of the system is increasing too. Hale [16] investigated existence and the local stable region of the Nash equilibrium point. Ma and Si [17] studied a continuous Bertrand duopoly game model with two-stage delay. Ma and Bangura [18] studied financial and economic system when the three parameters were changed.

By combining them, it is found that most of the studies are based on the discrete system, and the attention to the research of continuous system is not much, with lack of analysis from the in-system state and entropy theory, considering the delayed decision is less. Therefore, the model of [19] is improved based on the entropy theory and chaos theory, considering the three companies are bounded rationality and using a new cost function, and its chaotic characteristics and system entropy changes were analyzed. In the course of the study, the special case of $\tau_{1}=\tau_{2}=\tau$ is overcome, $\tau_{1} \neq \tau_{2}$, and $\tau_{1}>0, \tau_{2}>0$ are discussed. The improved model is more fit to the reality, and the research results are of guiding significance to the enterprise price decision.

This paper is organized as follows: in Section 2, based on [19], a triopoly price game model with delay is improved. In Section 3, the stability of system and the existence of Hopf bifurcation are analyzed. In Section 4, numerical simulation is used to find out the influence of delay on the stability of price and profit by virtue of time series, the attractor, bifurcation diagram, Lyapunov exponent, 3D surface chat, and initial value sensitivity, as well as the contacts between dynamic state and the situation of entropy change in the system. In Section 5, the effective control of chaos is achieved by control method of the state variables feedback and parameter variation in the system. Finally, we have some conclusions in the last section.

\section{The Model}

The triopoly dynamic game model is developed in [19] which makes adaptive decision, bounded rational decision, and delayed bounded rational decision, respectively. The stability of the system and the existence of Hopf bifurcation are studied in this paper. The model is described as follows:

$$
\begin{aligned}
& \dot{p}_{1}(t)=v_{1} p_{1}\left[\frac{\left(a+d_{1} w p_{2}(t)+d_{1}(1-w) p_{2}(t-\tau)+f_{1} p_{3}(t)+b_{1} c_{1}\right)}{\left(2 b_{1}\right)}-p_{1}(t-\tau)\right], \\
& \dot{p}_{2}(t)=v_{2} p_{2}\left[a-2 b_{2} w p_{2}(t)-2 b_{2}(1-w) p_{2}(t-\tau)+d_{2} p_{3}(t)+f_{2} p_{1}(t)+b_{2} c_{2}\right], \\
& \dot{p}_{3}(t)=v_{3} p_{3}\left[a-2 b_{3} p_{3}(t)+d_{3} p_{1}(t)+f_{3} w p_{2}(t)+f_{3}(1-w) p_{2}(t-\tau)+b_{3} c_{3}\right],
\end{aligned}
$$

where $a, b_{i}, d_{i}, f_{i}>0, i=1,2,3, a$ represents the largest market demand for products, $b_{i}$ is elastic demand, $d_{i}, f_{i}$ represents the substitution rate between the two companies, respectively, $p_{i}, q_{i}$ denote the price and output of the product, respectively, $0<w<1$ represents the weight of the current price, and $1-w$ represents the weight of price of $t-\tau$ time. The cost function with linear form is $C_{i}\left(q_{i}\right)=c_{i} q_{i}, i=1,2,3$, and $c_{i}$ is marginal profit. In (1), the first enterprise adopts the adaptive pricing strategy with delay, where $\tau_{1}$ denotes the delay parameter; the other two enterprises employ the finite rational pricing strategy. In addition, the second enterprise used the postponement strategy, where $\tau_{2}$ stands for the delay parameter. The linear cost function under the condition of sufficient resources was used. Then $\tau_{1}=\tau_{2}=\tau$ was discussed.

Because price information is asymmetry, we consider three companies are bounded rationality based on model [19] and build the price game model with enterprises 1 and 2 with delay parameters $\tau_{1}$ and $\tau_{2}$, respectively. The cost function will obviously increase under limited resources; that is, $C_{i}\left(q_{i}\right)=$ $c_{i 0}+c_{i} q_{i}^{2} i=1,2,3$, where $c_{i 0}$ is the fixed cost. We further have the improved model with price game:

$$
\begin{aligned}
& \dot{p}_{1}(t)=v_{1} p_{1}\left[\left(1+2 b_{1} c_{1}\right) a-\left(2 b_{1}+2 b_{1}^{2} c_{1}\right) p_{1}\left(t-\tau_{1}\right)\right. \\
& \left.+\left(d_{1}+2 b_{1} c_{1} d_{1}\right) p_{2}\left(t-\tau_{2}\right)+\left(f_{1}+2 b_{1} c_{1} f_{1}\right) p_{3}(t)\right] \\
& \dot{p}_{2}(t)=v_{2} p_{2}\left[\left(1+2 b_{2} c_{2}\right) a-\left(2 b_{2}+2 b_{2}^{2} c_{2}\right) p_{2}\left(t-\tau_{2}\right)\right. \\
& \left.\quad+\left(d_{2}+2 b_{2} c_{2} d_{2}\right) p_{3}(t)+\left(f_{2}+2 b_{2} c_{2} f_{2}\right) p_{1}\left(t-\tau_{1}\right)\right] \\
& \dot{p}_{3}(t)=v_{3} p_{3}\left[\left(1+2 b_{3} c_{3}\right) a-\left(2 b_{3}+2 b_{3}^{2} c_{3}\right) p_{3}(t)\right. \\
& \quad+\left(d_{3}+2 b_{3} c_{3} d_{3}\right) p_{1}\left(t-\tau_{1}\right) \\
& \left.\quad+\left(f_{3}+2 b_{3} c_{3} f_{3}\right) p_{2}\left(t-\tau_{2}\right)\right] .
\end{aligned}
$$

\section{Local Stability at Equilibrium Points}

In a competitive market, the equilibrium points must be nonnegative. Considering generality, we assume that $E_{*}\left(p_{1}^{*}, p_{2}^{*}, p_{3}^{*}\right)$ is a Nash equilibrium point of model (2), where 


$$
\begin{aligned}
& p_{1}^{*}>0, \\
& p_{2}^{*}>0, \\
& p_{3}^{*}>0 .
\end{aligned}
$$

We study the existence of Hopf bifurcation of the system at $E_{*}\left(p_{1}^{*}, p_{2}^{*}, p_{3}^{*}\right)$. Let $h_{1}(t)=p_{1}(t)-p_{1}^{*}, h_{2}(t)=p_{2}(t)-p_{2}^{*}$, and $h_{3}(t)=p_{3}(t)-p_{3}^{*}$, with $p_{1}(t), p_{2}(t)$, and $p_{3}(t)$ instead of $h_{1}(t), h_{2}(t)$, and $h_{3}(t)$, respectively, when $h=0$. We have the linear form of the system through Jacobian matrix as follows:

$$
\begin{aligned}
\dot{p}_{1}(t)= & -v_{1} p_{1}^{*}\left(2 b_{1}+2 b_{1}^{2} c_{1}\right) p_{1}\left(t-\tau_{1}\right) \\
& +v_{1} p_{1}^{*}\left(d_{1}+2 b_{1} c_{1} d_{1}\right) p_{2}\left(t-\tau_{2}\right) \\
& +v_{1} p_{1}^{*}\left(f_{1}+2 b_{1} c_{1} f_{1}\right) p_{3}(t), \\
\dot{p_{2}}(t)= & -v_{2} p_{2}^{*}\left(2 b_{2}+2 b_{2}^{2} c_{2}\right) p_{2}\left(t-\tau_{2}\right) \\
& +v_{2} p_{2}^{*}\left(d_{2}+2 b_{2} c_{2} d_{2}\right) p_{3}(t) \\
& +v_{2} p_{2}^{*}\left(f_{2}+2 b_{2} c_{2} f_{2}\right) p_{1}\left(t-\tau_{1}\right), \\
\dot{p}_{3}(t)= & -v_{3} p_{3}^{*}\left(2 b_{3}+2 b_{3}^{2} c_{3}\right) p_{3}(t) \\
& +v_{3} p_{3}^{*}\left(d_{3}+2 b_{3} c_{3} d_{3}\right) p_{1}\left(t-\tau_{1}\right) \\
& +v_{3} p_{3}^{*}\left(f_{3}+2 b_{3} c_{3} f_{3}\right) p_{2}\left(t-\tau_{2}\right) .
\end{aligned}
$$

The determinant of (4) is

$$
\left|\lambda E-J\left(E_{*}\right)\right|=0,
$$

where

$$
\begin{aligned}
J\left(E_{*}\right) & =\left|\begin{array}{lll}
J_{11} & J_{12} & J_{13} \\
J_{21} & J_{22} & J_{23} \\
J_{31} & J_{32} & J_{33}
\end{array}\right|, \\
J_{11} & =-v_{1} p_{1}^{*}\left(2 b_{1}+2 b_{1}^{2} c_{1}\right), \\
J_{12} & =v_{1} p_{1}^{*}\left(d_{1}+2 b_{1} c_{1} d_{1}\right), \\
J_{13} & =v_{1} p_{1}^{*}\left(f_{1}+2 b_{1} c_{1} f_{1}\right), \\
J_{21} & =v_{2} p_{2}^{*}\left(f_{2}+2 b_{2} c_{2} f_{2}\right), \\
J_{22} & =-v_{2} p_{2}^{*}\left(2 b_{2}+2 b_{2}^{2} c_{2}\right), \\
J_{23} & =v_{2} p_{2}^{*}\left(d_{2}+2 b_{2} c_{2} d_{2}\right), \\
J_{31} & =v_{3} p_{3}^{*}\left(d_{3}+2 b_{3} c_{3} d_{3}\right), \\
J_{32} & =v_{3} p_{3}^{*}\left(f_{3}+2 b_{3} c_{3} f_{3}\right), \\
J_{33} & =-v_{3} p_{3}^{*}\left(2 b_{3}+2 b_{3}^{2} c_{3}\right) .
\end{aligned}
$$

Therefore the characteristic equation for system (4) is

$$
\begin{gathered}
\lambda^{3}+k_{1} \lambda^{2}+\left(k_{2} \lambda^{2}+k_{3} \lambda\right) e^{-\lambda \tau_{1}}+\left(k_{4} \lambda^{2}+k_{5} \lambda\right) e^{-\lambda \tau_{2}} \\
+\left(k_{6} \lambda+k_{7}\right) e^{-\lambda \tau_{1}} e^{-\lambda \tau_{2}}=0,
\end{gathered}
$$

where

$$
\begin{aligned}
k_{1}= & 2 b_{3} p_{3}^{*} v_{3}+2 b_{3}^{2} c_{3} p_{3}^{*} v_{3}, \\
k_{2}= & 2 b_{1} p_{1}^{*} v_{1}+2 b_{1}^{2} c_{1} p_{1}^{*} v_{1}, \\
k_{3}= & 4 b_{1} b_{3} p_{1}^{*} p_{3}^{*} v_{1} v_{3}-d_{3} f_{1} p_{1}^{*} p_{3}^{*} v_{1} v_{3} \\
& +4 b_{1}^{2} b_{3} c_{1} p_{1}^{*} p_{3}^{*} v_{1} v_{3}+4 b_{1} b_{3}^{2} c_{3} p_{1}^{*} p_{3}^{*} v_{1} v_{3}+\cdots \\
& -2 b_{3} c_{3} d_{3} f_{1} p_{1}^{*} p_{3}^{*} v_{1} v_{3}, \\
k_{4}= & 2 b_{2} p_{2}^{*} v_{2}+2 b_{2}^{2} c_{2} p_{2}^{*} v_{2}, \\
k_{5}= & 4 b_{2} b_{3} p_{2}^{*} p_{3}^{*} v_{2} v_{3}-d_{2} f_{3} p_{2}^{*} p_{3}^{*} v_{2} v_{3} \\
& +4 b_{2}^{2} b_{3} c_{2} p_{2}^{*} p_{3}^{*} v_{2} v_{3}+4 b_{2} b_{3}^{2} c_{3} p_{2}^{*} p_{3}^{*} v_{2} v_{3}+\cdots \\
& -2 b_{3} c_{3} d_{2} f_{3} p_{2}^{*} p_{3}^{*} v_{2} v_{3}, \\
k_{6}= & 4 b_{1} b_{2} p_{1}^{*} p_{2}^{*} v_{1} v_{2}+4 b_{1}^{2} b_{2} c_{1} p_{1}^{*} p_{2}^{*} v_{1} v_{2} \\
& +4 b_{1} b_{2}^{2} c_{2} p_{1}^{*} p_{2}^{*} v_{1} v_{2}+\cdots \\
& -4 b_{1} b_{2} c_{1} c_{2} d_{1}^{2} f_{2} p_{1}^{*} p_{2}^{*} v_{1} v_{2}, \\
k_{7}= & 8 b_{1} b_{2} b_{3} p_{1}^{*} p_{2}^{*} p_{3}^{*} v_{1} v_{2} v_{3}-2 b_{1} d_{2} f_{3} p_{1}^{*} p_{2}^{*} p_{3}^{*} v_{1} v_{2} v_{3} \\
& +\cdots-8 b_{1} b_{2} b_{3} c_{1} c_{2} c_{3} d_{1}^{2} d_{2} d_{3} p_{1}^{*} p_{2}^{*} p_{3}^{*} v_{1} v_{2} v_{3} .
\end{aligned}
$$

We discuss the effects of $\tau_{1}, \tau_{2}$ on the stability of system (4) when $\tau_{1} \neq \tau_{2}, \tau_{1}>0, \tau_{2}>0$.

At this point, the characteristic equation of system (4) is

$$
\begin{aligned}
\lambda^{3}+ & k_{1} \lambda^{2}+\left(k_{2} \lambda^{2}+k_{3} \lambda\right) e^{-\lambda \tau_{1}}+\left(k_{4} \lambda^{2}+k_{5} \lambda\right) e^{-\lambda \tau_{2}} \\
& +\left(k_{6} \lambda+k_{7}\right) e^{-\lambda\left(\tau_{1}+\tau_{2}\right)}=0 .
\end{aligned}
$$

We consider (2) with $\tau_{2}$ in its stable range, regarding $\tau_{1}$ as a parameter. Taking into account the generality, we discuss system (2) under the case mentioned in [14], and $\tau_{2} \in\left[0, \tau_{20}\right)$. $\tau_{20}$ is defined as in [14]. Therefore we have

$$
\begin{aligned}
\tau_{2 k}^{(j)}= & \frac{1}{\omega_{2 k}} \arccos \left\{\frac{(D-A C) \omega_{2 k}^{4}+(A E-B D) \omega_{2 k}^{2}}{C^{2} \omega_{2 k}^{4}+\left(D^{2}-2 C E\right) \omega_{2 k}^{2}+E^{2}}\right\} \\
& +\frac{2 j \pi}{\omega_{2 k}}, \quad k=1,2,3,4,5, j=0,1,2, \ldots \\
\tau_{20}= & \min \left\{\tau_{2 k}^{(0)}\right\}, \quad k \in\{1,2,3,4,5\}, \omega_{20}=\omega_{2 k_{0}},
\end{aligned}
$$

where $\omega_{2 k}, i=1,2,3, \ldots, k$, are the positive roots of

$$
H_{1} \omega_{2}^{10}+H_{2} \omega_{2}^{8}+H_{3} \omega_{2}^{6}+H_{4} \omega_{2}^{4}+H_{5} \omega_{2}^{2}+H_{6}=0,
$$

where

$$
\begin{aligned}
H_{1}= & C^{2}, \\
H_{2}= & D^{2}-2 C E-2 B C^{2}+A^{2} C^{2}-C^{4}, \\
H_{3}= & 4 B C E+E^{2}+A^{2} D^{2}+B^{2} C^{2}+2 D^{2} B-2 A^{2} C E \\
& +4 C^{3} E-2 C^{2} D^{2},
\end{aligned}
$$




$$
\begin{aligned}
H_{4}= & A^{2} E^{2}-2 E^{2} B-2 B^{2} C E+B^{2} D^{2}-6 C^{2} E^{2}-D^{4} \\
& -4 C E D^{2}, \\
H_{5}= & B^{2} E^{2}-2 D^{2} E^{2}+4 C E^{3}, \\
H_{6}= & -E^{4}, \\
A= & k_{1}+k_{2}, \\
B= & k_{3}, \\
C= & k_{4}, \\
D= & k_{5}+k_{6}, \\
E= & k_{7} .
\end{aligned}
$$

Let $\lambda=i \omega_{1}\left(\omega_{1}>0\right)$ be a root of (9). Then

$$
\begin{aligned}
& A_{4} \sin \omega_{1} \tau_{1}+B_{4} \cos \omega_{1} \tau_{1}=\omega_{1}^{3}, \\
& C_{4} \sin \omega_{1} \tau_{1}+D_{4} \cos \omega_{1} \tau_{1} \\
& \quad=k_{1} \omega_{1}^{2}+k_{4} \omega_{1}^{2} \cos \omega_{1} \tau_{2}-k_{5} \omega_{1} \sin \omega_{1} \tau_{2},
\end{aligned}
$$

where

$$
\begin{aligned}
& A_{4}=k_{2} \omega_{1}^{2}-k_{6} \omega_{1} \sin \omega_{1} \tau_{2}-k_{7} \cos \omega_{1} \tau_{2}, \\
& B_{4}=k_{3} \omega_{1}+k_{6} \omega_{1} \cos \omega_{1} \tau_{2}-k_{7} \sin \omega_{1} \tau_{2}, \\
& C_{4}=k_{3} \omega_{1}+k_{6} \omega_{1} \cos \omega_{1} \tau_{2}-k_{7} \sin \omega_{1} \tau_{2}, \\
& D_{4}=k_{6} \omega_{1} \sin \omega_{1} \tau_{2}-k_{2} \omega_{1}^{2}+k_{7} \cos \omega_{1} \tau_{2} .
\end{aligned}
$$

For (13), we can obtain that

$$
\begin{aligned}
\sin \omega_{1} \tau_{1}= & \frac{N_{1} \omega_{1}^{4}+N_{2} \omega_{1}^{3}+N_{3} \omega_{1}^{2}+N_{4} \omega_{1}}{N_{10} \omega_{1}^{4}+N_{11} \omega_{1}^{3}+N_{12} \omega_{1}^{2}+N_{13} \omega_{1}+N_{14}}, \\
\cos \omega_{1} \tau_{1}= & \frac{N_{5} \omega_{1}^{5}+N_{6} \omega_{1}^{4}+N_{7} \omega_{1}^{3}+N_{8} \omega_{1}^{2}+N_{9} \omega_{1}}{N_{10} \omega_{1}^{4}+N_{11} \omega_{1}^{3}+N_{12} \omega_{1}^{2}+N_{13} \omega_{1}+N_{14}} \\
N_{1}= & k_{6} \cos \omega_{1} \tau_{2}-k_{2} k_{4} \cos \omega_{1} \tau_{2}-k_{1} k_{2}+k_{3}, \\
N_{2}= & k_{4} k_{6} \cos \omega_{1} \tau_{2} \sin \omega_{1} \tau_{2}+k_{1} k_{6} \sin \omega_{1} \tau_{2} \\
& -k_{7} \sin \omega_{1} \tau_{2}+k_{2} k_{5} \sin \omega_{1} \tau_{2}, \\
N_{3}= & k_{4} k_{7} \cos \omega_{1}^{2} \tau_{2}+k_{1} k_{7} \cos \omega_{1} \tau_{2} \\
& -k_{5} k_{6} \sin ^{2} \omega_{1} \tau_{2}, \\
N_{4}= & k_{5} k_{7} \cos \omega_{1} \tau_{2} \sin \omega_{1} \tau_{2} \\
N_{5}= & k_{2}, \\
N_{6}= & -k_{6} \sin \omega_{1} \tau_{2}, \\
N_{7}= & k_{1} k_{3}+k_{1} k_{6} \cos \omega_{1} \tau_{2}+k_{3} k_{4} \cos \omega_{1} \tau_{2} \\
& +k_{4} k_{6} \cos ^{2} \omega_{1} \tau_{2}-k_{7} \cos \omega_{1} \tau_{2},
\end{aligned}
$$

$$
\begin{aligned}
N_{8}= & k_{1} k_{7} \sin \omega_{1} \tau_{2}-k_{4} k_{7} \cos \omega_{1} \tau_{2} \sin \omega_{1} \tau_{2} \\
& +k_{5} k_{6} \sin \omega_{1} \tau_{2} \cos \omega_{1} \tau_{2} \\
& +k_{3} k_{5} \sin \omega_{1} \tau_{2}, \\
N_{9}= & k_{5} k_{7} \sin ^{2} \omega_{1} \tau_{2}, \\
N_{10}= & k_{2}^{2}, \\
N_{11}= & -2 k_{2} k_{6} \sin \omega_{1} \tau_{2}, \\
N_{12}= & k_{3}^{2}+2 k_{3} k_{6} \cos \omega_{1} \tau_{2}+k_{6}^{2}-2 k_{2} k_{7} \cos \omega_{1} \tau_{2}, \\
N_{13}= & -2 k_{3} k_{7} \sin \omega_{1} \tau_{2}, \\
N_{14}= & k_{7}^{2} .
\end{aligned}
$$

For (15), we obtain the following equation:

$$
\begin{aligned}
M_{10} & \omega_{1}^{10}+M_{9} \omega_{1}^{9}+M_{8} \omega_{1}^{8}+M_{7} \omega_{1}^{7}+M_{6} \omega_{1}^{6}+M_{5} \omega_{1}^{5} \\
\quad & M_{4} \omega_{1}^{4}+M_{3} \omega_{1}^{3}+M_{2} \omega_{1}^{2}+M_{1} \omega_{1}+M_{0}=0, \\
M_{10} & =N_{5}^{2}, \\
M_{9} & =N_{1}^{2} N_{6}^{2}+2 N_{5} N_{7}-N_{10}^{2}, \\
M_{8} & =2 N_{5} N_{6}, \\
M_{7} & =2 N_{1} N_{2}+2 N_{5} N_{8}+2 N_{6} N_{7}-2 N_{10} N_{11}, \\
M_{6}= & N_{2}^{2}+2 N_{1} N_{3}+N_{7}^{2}+2 N_{6} N_{8}+2 N_{5} N_{9}-N_{11}^{2} \\
\quad & 2 N_{10} N_{12}, \\
M_{5}= & 2 N_{1} N_{4}+2 N_{2} N_{3}+2 N_{7} N_{8}+2 N_{6} N_{9} \\
\quad & 2 N_{10} N_{13}-2 N_{11} N_{12}, \\
M_{4}= & N_{3}^{2}+2 N_{2} N_{4}+N_{8}^{2}+2 N_{7} N_{9}-N_{12}^{2}-2 N_{11} N_{13} \\
\quad & 2 N_{10} N_{14}, \\
M_{3}= & 2 N_{3} N_{4}+2 N_{8} N_{9}-2 N_{12} N_{13}-2 N_{11} N_{14}, \\
M_{2}= & N_{4}^{2}+N_{9}^{2}-N_{13}^{2}-2 N_{12} N_{14}, \\
M_{1}= & -2 N_{13} N_{14}, \\
M_{0}= & -N_{14}^{2} .
\end{aligned}
$$

Suppose that (H1): (16) has finite positive roots. We define the roots of (16) as $\omega_{11}, \omega_{12}, \omega_{13}, \ldots, \omega_{1 k}$. For every fixed $\omega_{1 i}$ $(i=1,2,3, \ldots, k)$, there exists a sequence $\tau_{1 i}^{(j)} \mid j=0,1,2, \ldots$ which satisfies (16). It is

$$
\begin{aligned}
\tau_{1 i}^{(j)} & =\frac{1}{\omega_{1 i}} \\
\cdot & \arccos \left\{\frac{N_{5} \omega_{1 i}^{5}+N_{6} \omega_{1 i}^{4}+N_{7} \omega_{1 i}^{3}+N_{8} \omega_{1 i}^{2}+N_{9} \omega_{1 i}}{N_{10} \omega_{1 i}^{4}+N_{11} \omega_{1 i}^{3}+N_{12} \omega_{1 i}^{2}+N_{13} \omega_{1 i}+N_{14}}\right\} \\
& +\frac{2 j \pi}{\omega_{1 i}}, \quad i=1,2,3, \ldots, k, j=0,1,2, \ldots
\end{aligned}
$$


Let

$$
\begin{aligned}
\tau_{10} & =\min \left\{\tau_{1 i}^{(j)} \mid i=1,2,3, \ldots, k, j=0,1,2, \ldots\right\}, \\
\omega_{10} & =\omega_{1 i_{0}} .
\end{aligned}
$$

When $\tau_{1}=\tau_{10},(9)$ has a pair of purely imaginary roots $\pm i \omega_{10}$ for $\tau_{2} \in\left[0, \tau_{20}\right)$. In the following, we take the derivative of $\lambda$ with respect to $\tau_{1}$ in (9) for the transversality condition of Hopf bifurcation, and we have

$$
\left[\frac{d \lambda}{d \tau_{1}}\right]^{-1}=\frac{-3 \lambda^{2}-2 k_{1} \lambda-\left(2 k_{2} \lambda+k_{3}\right) e^{-\lambda \tau_{1}}-\left(2 k_{4}+k_{5}\right) e^{-\lambda \tau_{2}}-k_{6} e^{-\left(\tau_{1}+\tau_{2}\right)}}{\left(k_{2} \lambda^{3}+k_{3} \lambda^{2}\right) e^{-\lambda \tau_{1}}+\left(k_{4} \lambda^{3}+k_{5} \lambda^{2}\right) e^{-\lambda \tau_{2}}+\left(k_{6} \lambda+k_{7} \lambda\right) e^{-\lambda\left(\tau_{1}+\tau_{2}\right)}}-\frac{\tau_{1}}{\lambda} .
$$

Then we further have

$$
\left[\frac{d \lambda\left(\tau_{10}\right)}{d \tau_{1}}\right]_{\lambda=i \omega_{10}}^{-1}=\frac{S_{1} S_{3}+S_{2} S_{4}}{S_{3}^{2}+S_{4}^{2}}
$$

where

$$
\begin{aligned}
S_{1}= & 3 \omega_{10}^{2}-2 k_{2} \omega_{10} \sin \omega_{10} \tau_{10}+k_{3} \cos \omega_{10} \tau_{10} \\
& -2 k_{4} \omega_{10} \sin \omega_{10} \tau_{2}-k_{5} \cos \omega_{10} \tau_{2} \\
& -k_{6} \cos \left(\omega_{10} \tau_{10}-\omega_{10} \tau_{2}\right), \\
S_{2}= & k_{5} \sin \omega_{10} \tau_{2}-2 k_{1} \omega_{10}-2 k_{2} \omega_{10} \cos \omega_{10} \tau_{10} \\
& -k_{3} \sin \omega_{10} \tau_{10}-2 k_{4} \omega_{10} \cos \omega_{10} \tau_{2} \\
& -k_{6} \sin \left(\omega_{10} \tau_{10}+\omega_{10} \tau_{2}\right), \\
S_{3}= & -k_{2} \omega_{10}^{3} \sin \omega_{10} \tau_{10}-k_{3} \omega_{10}^{2} \cos \omega_{10} \tau_{10} \\
& -k_{4} \omega_{10}^{3} \sin \omega_{10} \tau_{2}-k_{5} \omega_{10}^{2} \cos \omega_{10} \tau_{2} \\
& +\left(k_{6}+k_{7}\right) \omega_{10} \sin \left(\omega_{10} \tau_{10}+\omega_{10} \tau_{2}\right) \\
S_{4}= & -k_{2} \omega_{10}^{3} \cos \omega_{10} \tau_{10}+k_{3} \omega_{10}^{2} \sin \omega_{10} \tau_{10} \\
& -k_{4} \omega_{10}^{3} \cos \omega_{10} \tau_{2}+k_{5} \omega_{10}^{2} \sin \omega_{10} \tau_{2} \\
& +\left(k_{6}+k_{7}\right) \omega_{10} \cos \left(\omega_{10} \tau_{10}+\omega_{10} \tau_{2}\right) .
\end{aligned}
$$

Obviously, if (H2): $S_{1} S_{3}+S_{2} S_{4} \neq 0$, based on the above discussions and by the general Hopf bifurcation theorem in [15], we can obtain the results as follows.

If $H(1)-H(2)$ hold, when $\tau_{2} \in\left[0, \tau_{20}\right)$, then the Nash equilibrium point $E_{*}\left(p_{1}^{*}, p_{2}^{*}, p_{3}^{*}\right)$ of system (2) is asymptotically stable for $\tau_{1} \in\left[0, \tau_{10}\right)$ and it is unstable as $\tau_{1}>\tau_{10}$. System (2) will be under Hopf bifurcation at $E_{*}\left(p_{1}^{*}, p_{2}^{*}, p_{3}^{*}\right)$ when $\tau_{1}=\tau_{10}$.

\section{Numerical Simulations}

The impacts of delay on the stability of system (2) are analyzed by a series of tools in this section. It supports the theoretical research in Section 3 by time series, bifurcation, Lyapunov exponents, attractor, and initial value sensitivity.

The parameters of system (2) are taken to be $a=5, b_{1}=$ $3.2, b_{2}=3.5, b_{3}=3.8, d_{1}=0.3, d_{2}=0.4, d_{3}=0.5, f_{1}=0.35$, $f_{2}=0.45$, and $f_{3}=0.55$; the marginal costs of three dairy product companies are $c_{1}=0.003, c_{2}=0.006$, and $c_{3}=0.009$; the initial prices of their products are $p_{1}(0)=0.4, p_{2}(0)=0.5$, and $p_{3}(0)=0.6$; the speeds of price adjustment are $v_{1}=v_{2}=$ $v_{3}=0.5$; the fixed cost of the enterprise is $c_{10}=1, c_{20}=1.5$, and $c_{30}=2$. Considering the following system, it is easy to calculate the Nash equilibrium point of system (2) which is $E_{*}(0.8723,0.8329,0.8012)$.

$$
\begin{gathered}
\dot{p_{1}}(t)=0.20\left(5.0960-6.4614 p_{1}\left(t-\tau_{1}\right)\right. \\
\left.+0.3058 p_{2}\left(t-\tau_{2}\right)+0.3567 p_{3}(t)\right) \\
\dot{p_{2}}(t)=0.25\left(5.2100-7.1470 p_{2}\left(t-\tau_{2}\right)\right. \\
\left.+0.4168 p_{3}(t)+0.4689 p_{1}\left(t-\tau_{1}\right)\right) \\
\dot{p_{3}}(t)=0.30\left(5.3420-7.8599 p_{3}(t)\right. \\
\left.+0.5342 p_{1}\left(t-\tau_{1}\right)+0.5876 p_{2}\left(t-\tau_{2}\right)\right) .
\end{gathered}
$$

From (10) and (11), we can get $\omega_{20}=3.612, \tau_{20}=0.508$. In order to facilitate the calculation, let $\tau_{2}=0.45 \in\left[0, \tau_{20}\right)$. On the basis of (18), we have $\tau_{10}=0.547, S_{1} S_{3}+S_{2} S_{4}=512.74 \neq 0$, so $(H 1)-(H 2)$ hold. From the conclusion of the third section, we know that the Nash equilibrium point $E_{*}$ is asymptotically stable when $\tau_{1} \in\left[0, \tau_{10}\right)$ and unstable when $\tau_{1}>\tau_{10}$. As $\tau_{1}=$ $\tau_{10}$, Hopf bifurcation will occur.

4.1. The Influence of $\tau_{1}$ on the Stability of System (22). Figures (a) and 2(a) show that system (22) is stable when $\tau_{1}=$ $0.530<\tau_{10}=0.547$. When $\tau_{1}=0.560>\tau_{10}=0.547$, the system is unstable. This phenomenon can be found in Figures 1(b) and 2(b). The numerical simulation is consistent with the theoretical analysis.

Figure 3 describes the process of system (22) from stable into chaos. From Figure 3(a), we can find that the system has bifurcation, and $\tau_{1}$ has the greatest impact on $p_{1}$ and has less influence on $p_{2}$. The change trend of the Lyapunov exponent in Figure 3(b) verifies the conclusion of Figure 3(a) $p_{3}$. We clearly find the bifurcation of system (22) when $\tau_{1}=0.547$ in Figure 3(b). Therefore, for enterprises in the price decision, it is necessary to ensure that $\tau_{1}<0.547$ when $\tau_{2}=0.45$.

4.2. The Influence of $\tau_{1}$ on Initial Value Sensitivity. If we take the initial value of $p_{1}$ is 0.4 and 0.401 , respectively, the value of $p_{1}$ will change after iterations. When $\tau_{1}=0.530<\tau_{10}=$ 0.547 , after 61 iterations, the difference of $p_{1}$ is 6.144 times of the initial difference 0.001 . It can be described by Figure 4(a). 

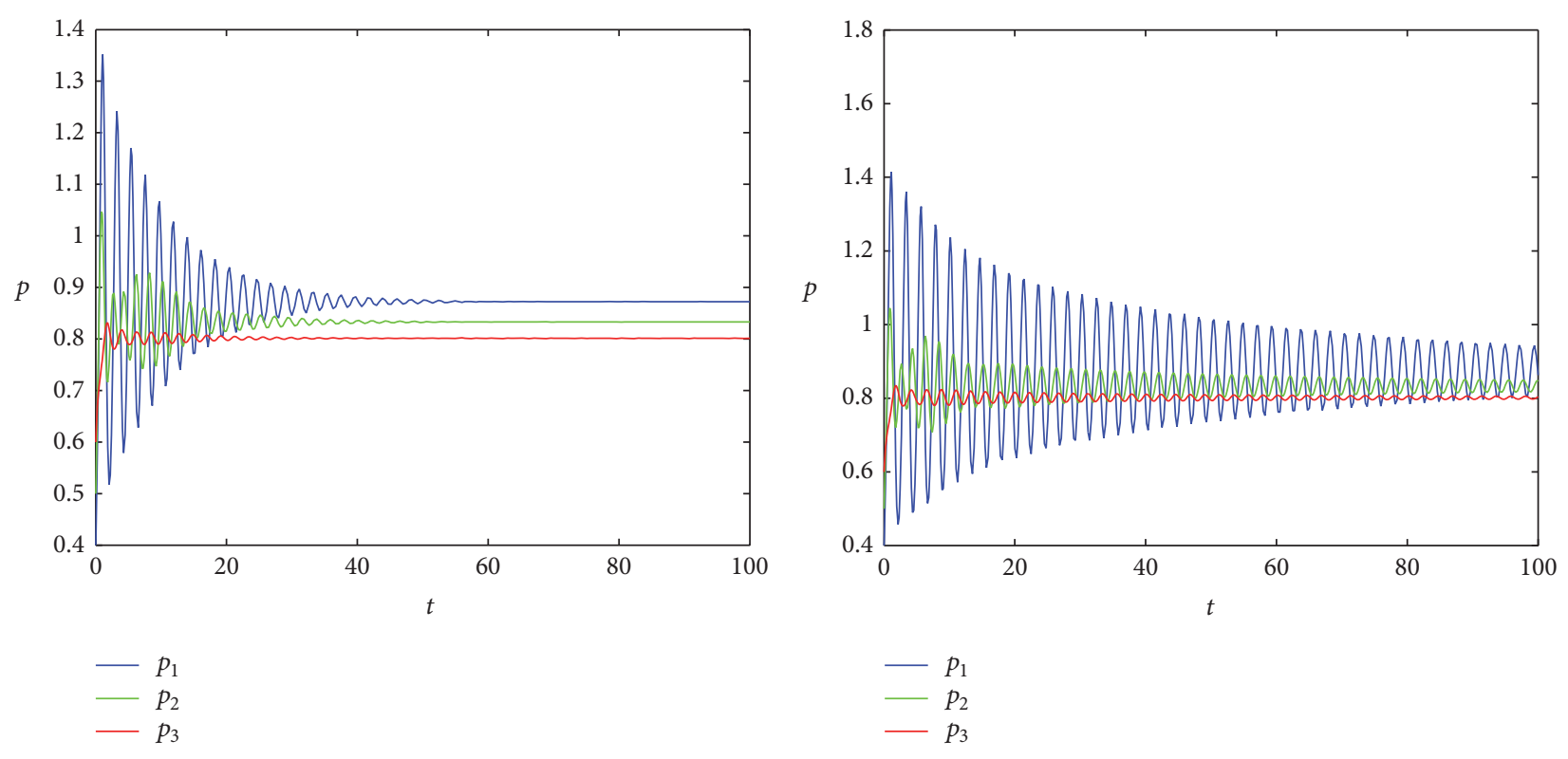
(a) $\tau_{1}=0.530<\tau_{10}=0.547$
(b) $\tau_{1}=0.560>\tau_{10}=0.547$

Figure 1: The time series of system (22) when $\tau_{2}=0.45$.

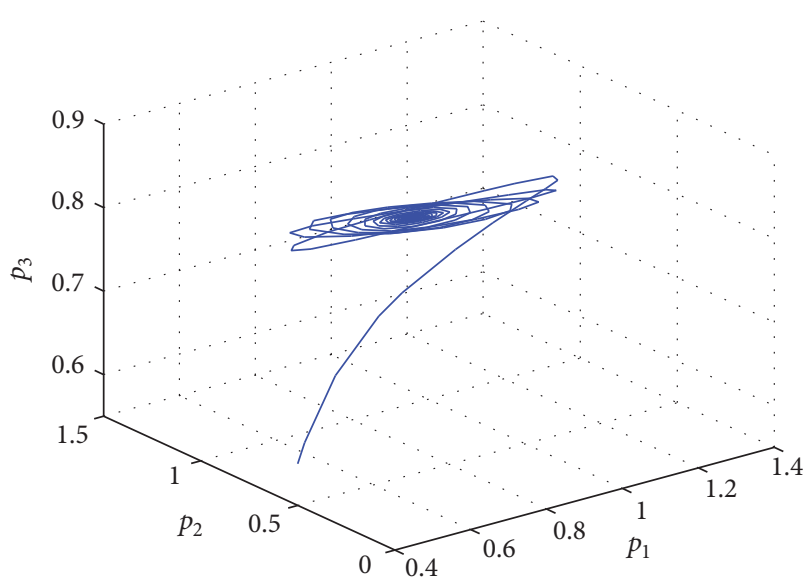

(a) $\tau_{1}=0.530<\tau_{10}=0.547$

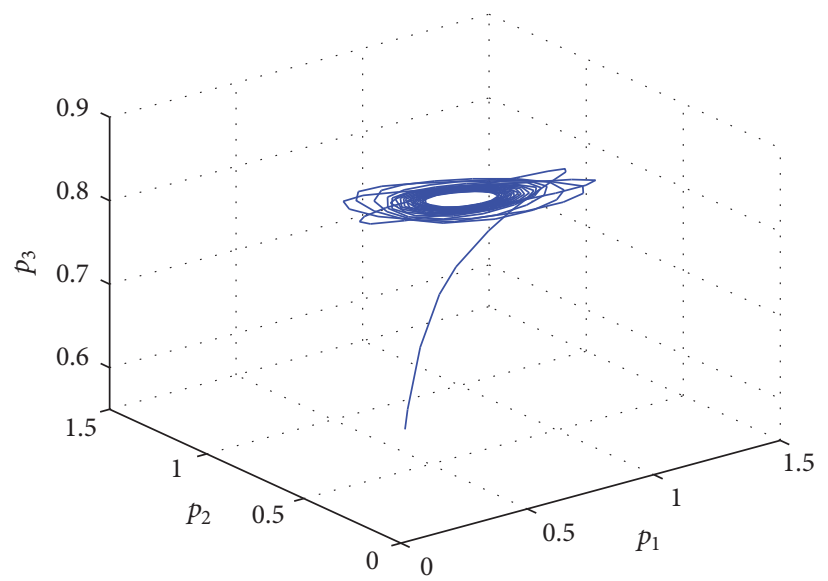

(b) $\tau_{1}=0.560>\tau_{10}=0.547$

FIgURE 2: The attractor of system (22) when $\tau_{2}=0.45$.

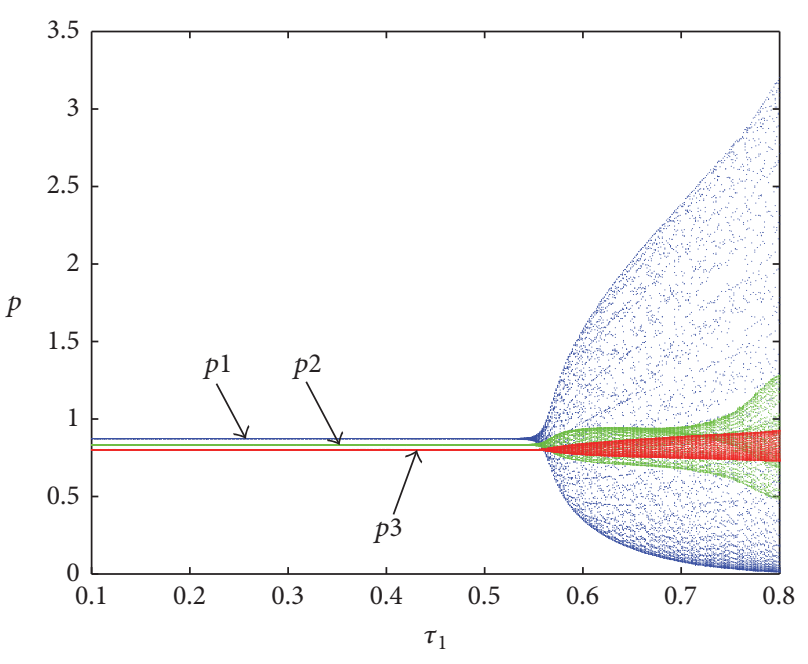

(a) Price bifurcation

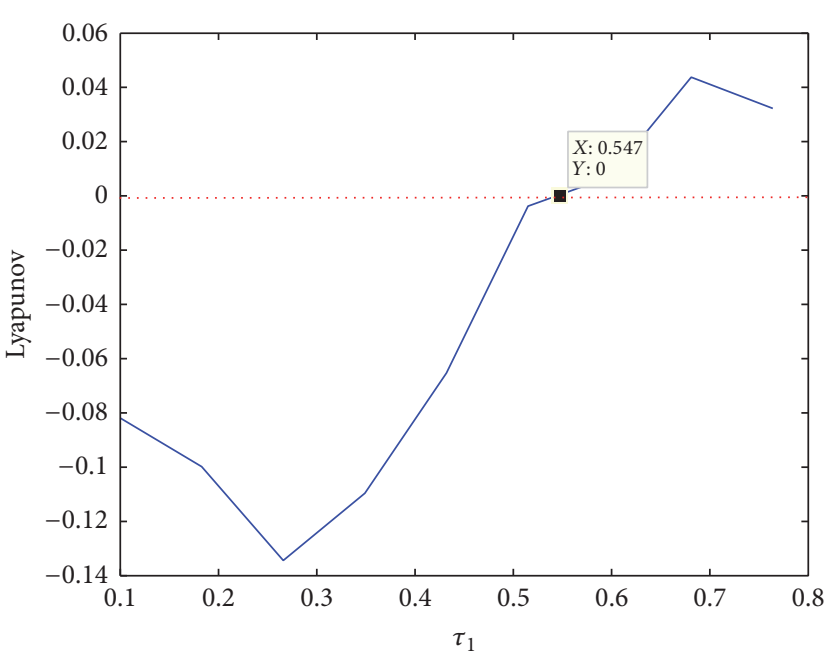

(b) The biggest Lyapunov exponent

FIgURE 3: The influence of $\tau_{1}$ on system (22) when $\tau_{2}=0.45$. 


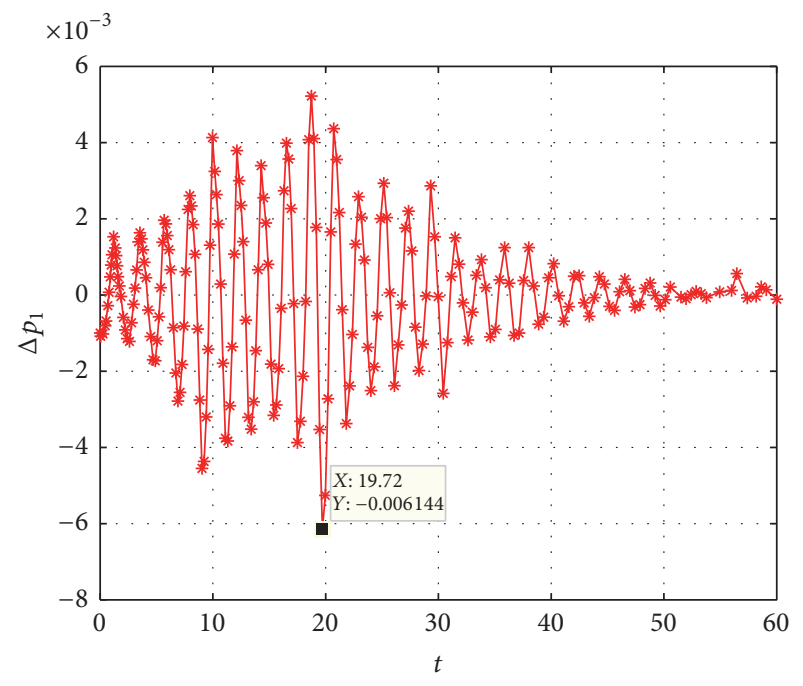

(a) $\tau_{1}=0.530<\tau_{10}=0.547$

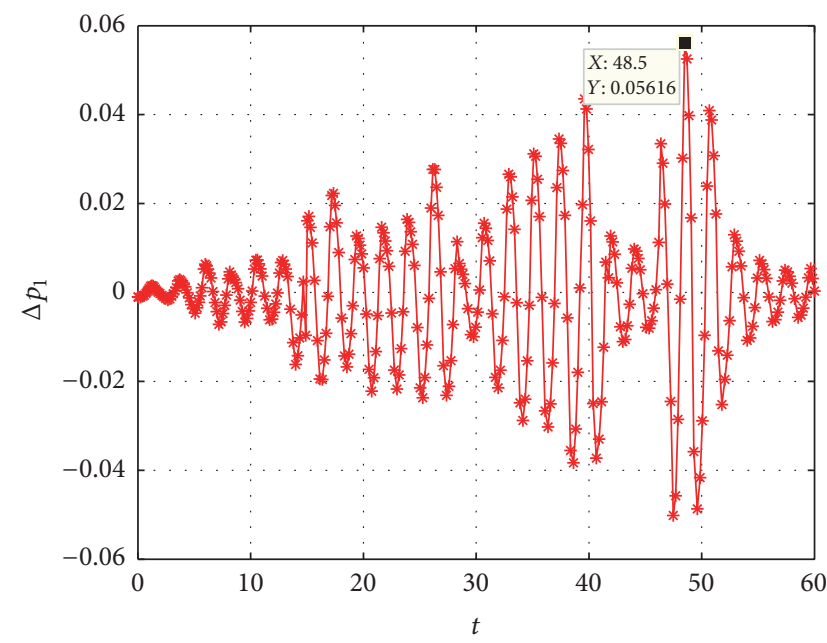

(b) $\tau_{1}=0.560>\tau_{10}=0.547$

FIgure 4: The sensitivity of $p_{1}$ to initial value $(0.4,0.401)$ when $\tau_{2}=0.45$.

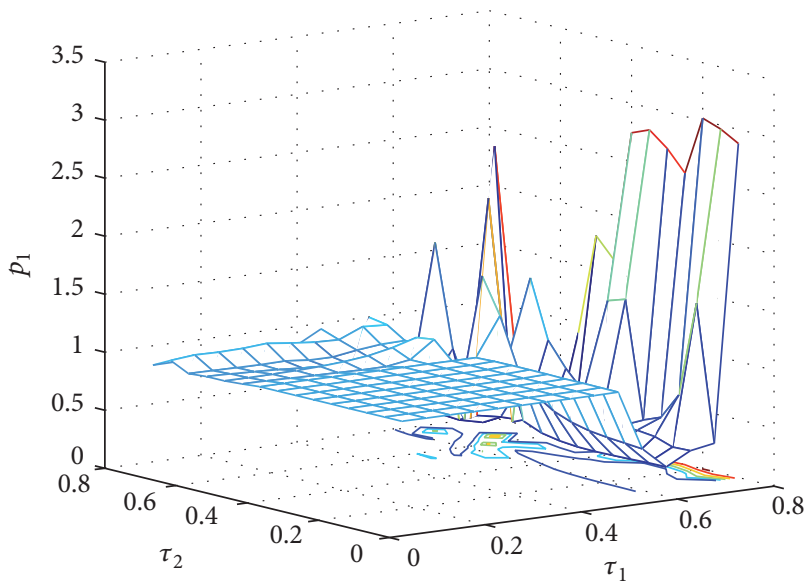

FIgUre 5: The influence of $\tau_{1}$ and $\tau_{2}$ on price.

In Figure 4(b), when $\tau_{1}=0.560>\tau_{10}=0.547$, after 61 iterations, the difference of $p_{1}$ is 56.16 times of the initial difference 0.001 . At this point, the value of $p_{1}$ has strong dependence on the initial value. Therefore, we know that system (22) is already in chaos. So we can infer that price decisions-making will have many unpredictable, tiny price adjustments which will have a greater price deviation.

4.3. The Influence of $\tau_{1}$ and $\tau_{2}$ on Stability of Price. We take $\tau_{1}$ and $\tau_{2}$ as parameters to study the effects of $\tau_{1}$ and $\tau_{2}$ on the price stability. With the increase of $\tau_{1}$ and $\tau_{2}$, the price changed from stable to unstable in Figure 5. When $\tau_{1}$ is greater than 0.52 , the price will experience fluctuations; when $\tau_{2}$ is more than 0.5 , the price will lose stability. When price is stable, the price will be stable at 0.8723 . When price is chaotic, the highest price is 2.967 for $\tau_{1}=0.8, \tau_{2}=0.15$; the lowest price is 0.01871 for $\tau_{1}=0.75, \tau_{2}=0.75$. Therefore, enterprises

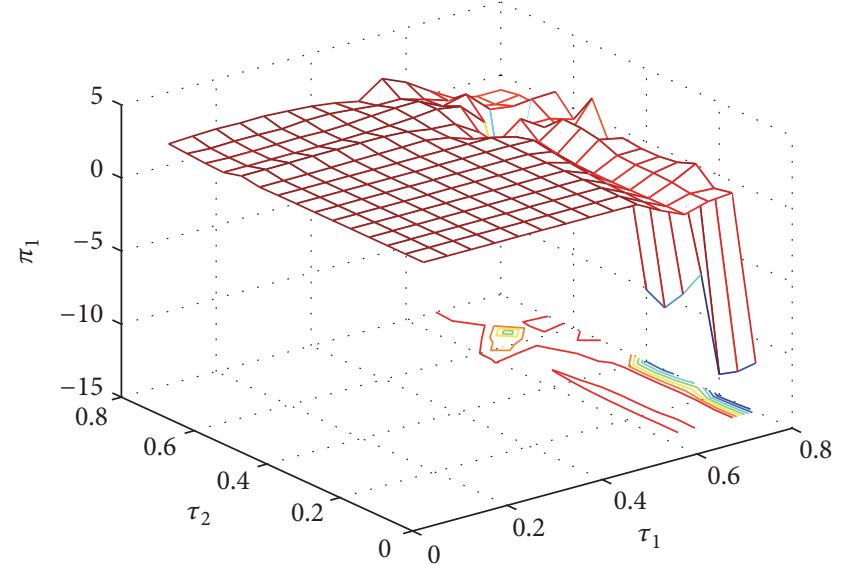

FIgURE 6: The influence of $\tau_{1}$ and $\tau_{2}$ on profit.

should ensure that $\tau_{1}$ and $\tau_{2}$ are in a reasonable range when the price is set.

4.4. The Influence of $\tau_{1}$ and $\tau_{2}$ on Stability of Profit. We can see from Figure 6, when $\tau_{1}>0.52$, the profit will be unstable; when $\tau_{2}>0.5$, the profit will fluctuate. As profit is in stable condition, the profit is stable at 1.367 . When the profit is in an unstable state, the maximum profit is 1.367 ; the lowest profit is -13.6 for $\tau_{1}=0.8, \tau_{2}=0.2$. Through the analysis we can know that with the increase of $\tau_{1}$ and $\tau_{2}$, profit will decline but not higher than the stable value. Therefore, enterprises must maintain a reasonable value of $\tau_{1}$ and $\tau_{2}$; otherwise there will be a loss.

\section{Chaos Control}

From the above analysis, we realize that the price and profit are in a state of chaos, which can lead to the fluctuation of 

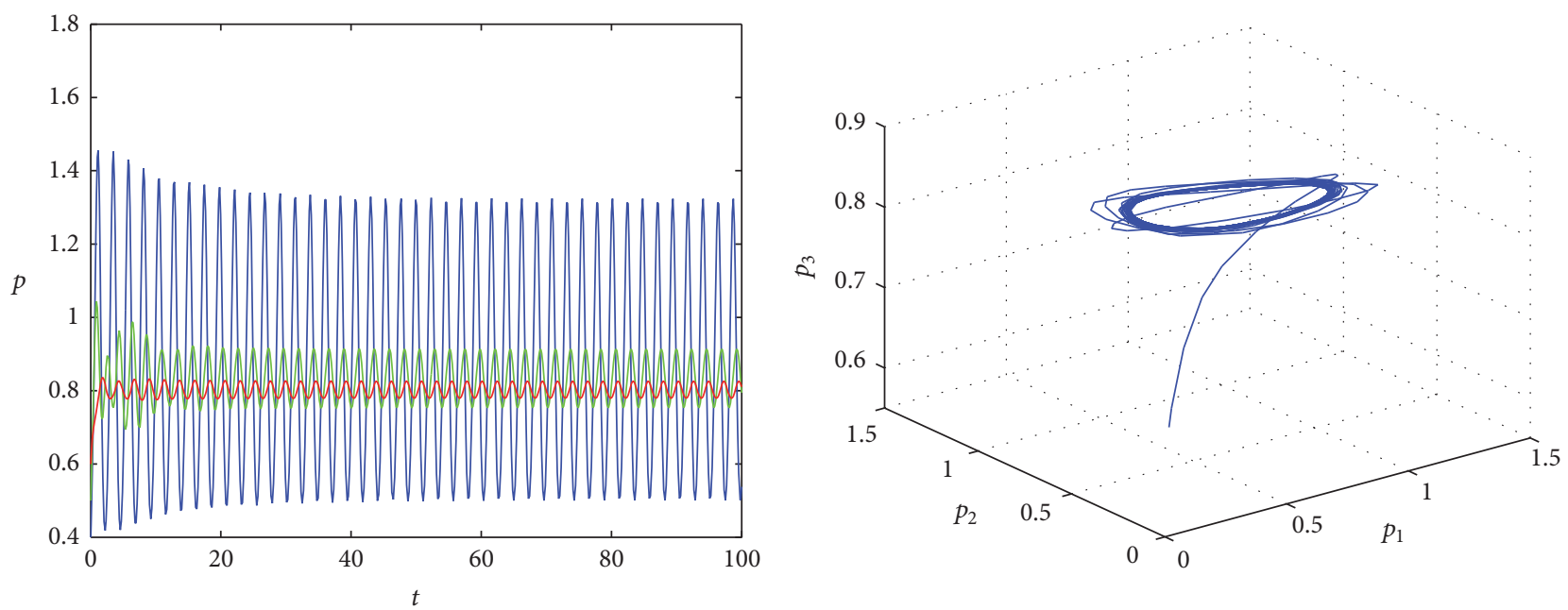

$-p_{1}$
$-p_{2}$
$-p_{3}$

(a) Time series

(b) Attractor

FIGURE 7: The time series and attractor $\tau_{1}=0.58, \tau_{2}=0.45$.

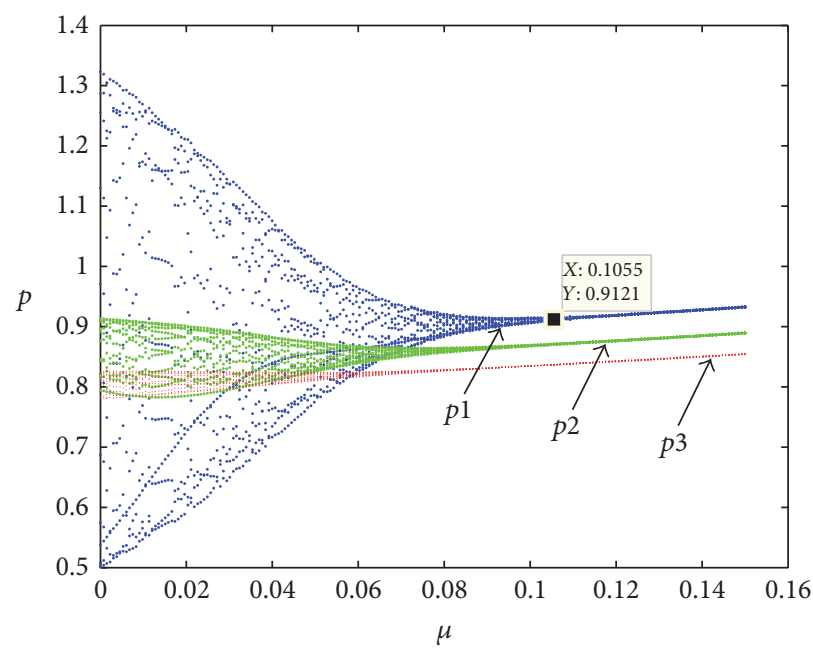

(a) Bifurcation

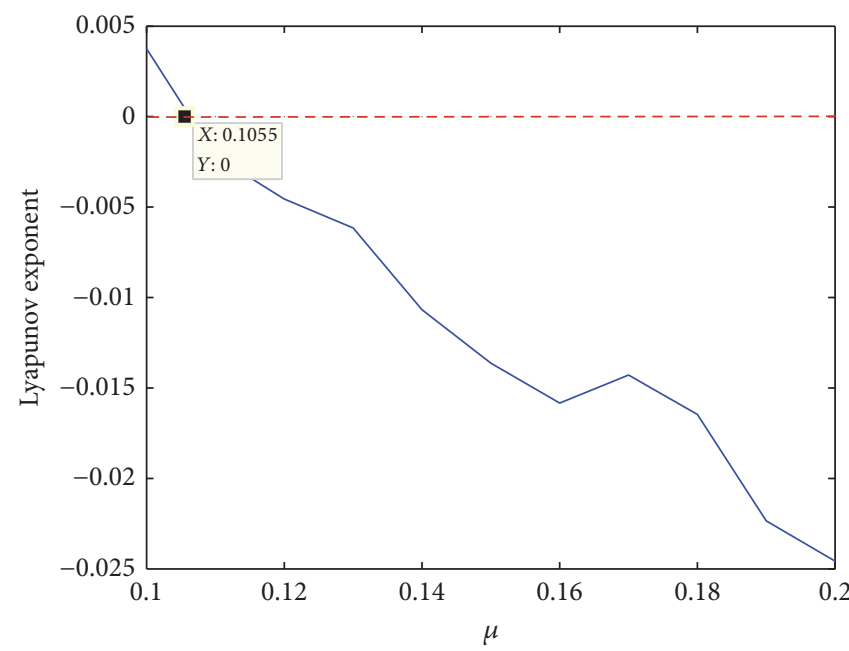

(b) Lyapunov exponents

FIGURE 8: The influence of $\mu$ on the system when $\tau_{1}=0.58, \tau_{2}=0.45$.

the price and the profit. Therefore, we should take measures to prevent the system from entering a chaotic state or make it recover to a stable state. Below we take the method of the state variables feedback and parameter variation to control the system. Let $\tau_{1}=0.58$ and $\tau_{2}=0.45$; we can find that the system is chaotic from Figure 5. The time series and attractor of system (2) when $\tau_{1}=0.58, \tau_{2}=0.45$ are shown in Figure 7 .

Adding control variable $\mu$ in system (22), then system (22) becomes

$$
\begin{aligned}
& \dot{p_{1}}(t)=(1-\mu) 0.20\left(5.0960-6.4614 p_{1}\left(t-\tau_{1}\right)\right. \\
& \left.\quad+0.3058 p_{2}\left(t-\tau_{2}\right)+0.3567 p_{3}(t)\right)+\mu p_{1}(t)
\end{aligned}
$$

$$
\begin{aligned}
& \dot{p_{2}}(t)=(1-\mu) 0.25\left(5.2100-7.1470 p_{2}\left(t-\tau_{2}\right)\right. \\
& \left.\quad+0.4168 p_{3}(t)+0.4689 p_{1}\left(t-\tau_{1}\right)\right)+\mu p_{2}(t), \\
& \dot{p_{3}}(t)=(1-\mu) 0.30\left(5.3420-7.8599 p_{3}(t)\right. \\
& \left.\quad+0.5342 p_{1}\left(t-\tau_{1}\right)+0.5876 p_{2}\left(t-\tau_{2}\right)\right)+\mu p_{3}(t) .
\end{aligned}
$$

The effect of $\mu$ on system (23) is shown in Figure 8. We can get that when $\mu=0.1055$, system (23) has bifurcation phenomenon. That is to say, when $\mu<0.1055$, system (23) is chaotic, and when $\mu>0.1055$, system (23) is stable. With the 


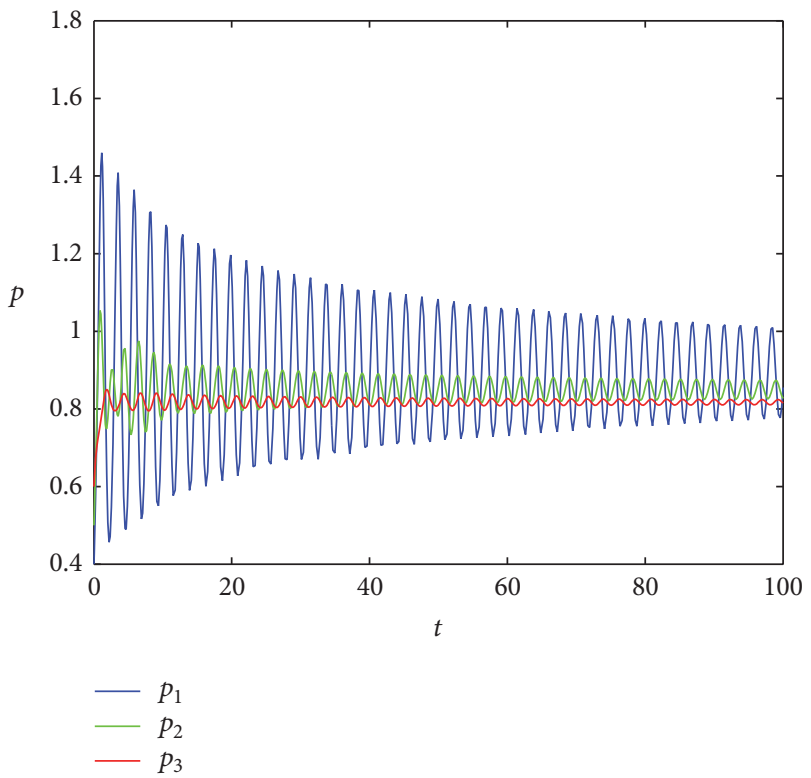

(a) Time series

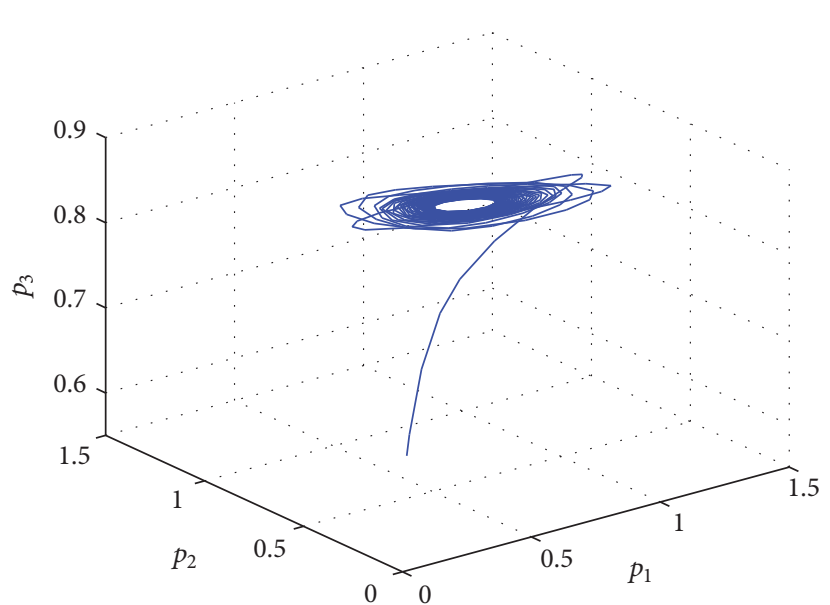

(b) Attractor

FIgURE 9: The time series and attractor when $\mu=0.05<0.1055$.

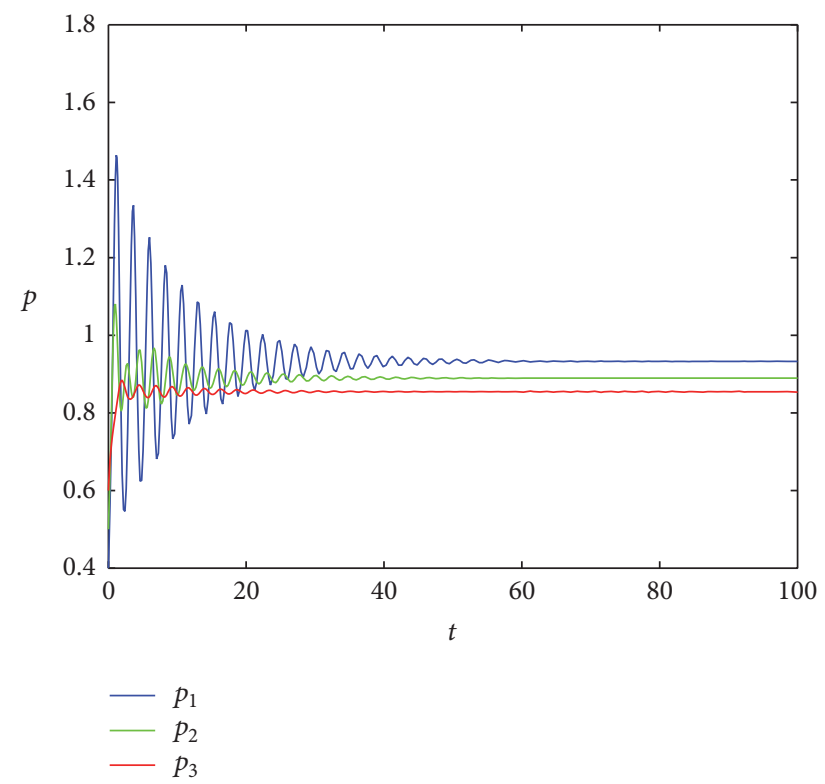

(a) Time series

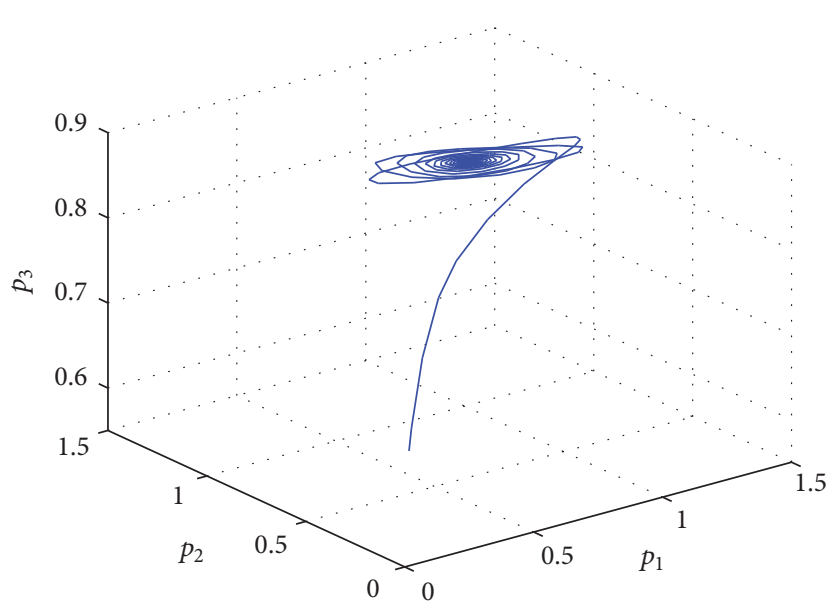

(b) Attractor

FIGURE 10: The time series and attractor when $\mu=0.15>0.1055$.

increase of $\mu$, the system changes from chaotic state to stable state.

Let $\mu=0.05<0.1055$; we can find that system (23) is chaotic from Figure 8 . The time series and attractor of system (23) are shown in Figure 9.

Let $\mu=0.15>0.1055$; we can see that system (23) is stable from Figure 8 . The time series and attractor of system (23) are shown in Figure 10. Compared with Figures 9 and 10, chaos is controlled. The bigger the value of $\mu$ is, the more obvious the control effect is.

\section{Conclusions}

The model of [19] was improved considering three enterprises are bounded rationality and using the cost function under the resource constraints. At the same time, delay strategy was used by the first and second enterprises. Firstly, when $\tau_{2}$ is fixed, the influence of $\tau_{1}$ on the stability of the system is considered. Secondly, the effects of $\tau_{1}, \tau_{2}$ on the stability of price and profit were studied. The research shows that the value of $\tau_{1}$ and $\tau_{2}$ must be ensured in a reasonable range, 
and the price and profit are stable; otherwise there will be violent fluctuations. Finally, measures are taken to control chaos of system (2) successfully. The results of the paper play an important guiding value for the enterprise to carry on the price decision.

\section{Conflicts of Interest}

The authors declare no conflicts of interest.

\section{Acknowledgments}

The paper is supported by "The Fundamental Research Funds for the Central Universities," South-Central University for Nationalities (CSY13011). The authors extend their gratitude to Fengshan Si, Yuhua Xu, and Junjie Li for their help in model building and computing.

\section{References}

[1] J. Zhang, D. Zhou, and Y. Wang, "Complex dynamics analysis for a Bertrand duopoly model with bounded rationality," in Proceedings of the International Conference on Management Science and Engineering (ICMSE '09), Moscow, Russia, September 2009.

[2] W. Xu and J. Ma, "Study on the dynamic model of a duopoly game with delay in insurance market," WSEAS Transactions on Mathematics, vol. 11, no. 7, pp. 615-624, 2012.

[3] Z. Sun and J. Ma, "Complexity of triopoly price game in Chinese cold rolled steel market," Nonlinear Dynamics. An International Journal of Nonlinear Dynamics and Chaos in Engineering Systems, vol. 67, no. 3, pp. 2001-2008, 2012.

[4] J. Dajka, M. Łobejko, and J. Sładkowski, "Payoffs and coherence of a quantum two-player game in a thermal environment," Entropy, vol. 17, no. 12, pp. 7736-7751, 2015.

[5] L. Fanti, L. Gori, C. Mammana, and E. Michetti, "The dynamics of a Bertrand duopoly with differentiated products: synchronization, intermittency and global dynamics," Chaos, Solitons \& Fractals, vol. 52, pp. 73-86, 2013.

[6] Z. Xiangyu and Q. Xiaoyong, "A research on measure model of market structure entropy under the condition of competition and monopoly," Journal of Industrial Technological Economics, vol. 2, article 011, 2013.

[7] A. K. Naimzada and F. Tramontana, "Dynamic properties of a Cournot-Bertrand duopoly game with differentiated products," Economic Modelling, vol. 29, no. 4, pp. 1436-1439, 2012.

[8] T. Li and J. Ma, "The complex dynamics of R\&D competition models of three oligarchs with heterogeneous players," Nonlinear Dynamics, vol. 74, no. 1-2, pp. 45-54, 2013.

[9] Y. Fan, T. Xie, and J. Du, "Complex dynamics of duopoly game with heterogeneous players: a further analysis of the output model," Applied Mathematics and Computation, vol. 218, no. 15, pp. 7829-7838, 2012.

[10] L. U. Yali, "Dynamics of a delayed Duopoly game with increasing marginal costs and bounded rationality strategy," Procedia Engineering, vol. 15, pp. 4392-4396, 2011.

[11] X. Gao, W. Zhong, and S. Mei, "Equilibrium stability of a nonlinear heterogeneous duopoly game with extrapolative foresight," Mathematics and Computers in Simulation, vol. 82, no. 11, pp. 2069-2078, 2012.
[12] J. Peng, Z. Miao, and F. Peng, "Study on a 3-dimensional game model with delayed bounded rationality," Applied Mathematics and Computation, vol. 218, no. 5, pp. 1568-1576, 2011.

[13] G. I. Bischi and A. Naimzada, "Global analysis of a dynamic duopoly game with bounded rationality," in Advances in Dynamic Games and Applications (Kanagawa, 1996), vol. 5, pp. 361-385, Birkhauser Boston, Boston, Mass, USA, 2000.

[14] J. Ma and H. Tu, "Analysis of the stability and Hopf bifurcation of money supply delay in complex macroeconomic models," Nonlinear Dynamics, vol. 76, no. 1, pp. 497-508, 2014.

[15] J. Ma and H. Wang, "Complexity analysis of dynamic noncooperative game models for closed-loop supply chain with product recovery," Applied Mathematical Modelling, vol. 38, no. 23, pp. 5562-5572, 2014.

[16] J. Hale, Theory of Functional Differential Equations, Springer, New York, NY, USA, 2nd edition, 1977.

[17] J. Ma and F. Si, "Complex dynamics of a continuous Bertrand duopoly game model with two-stage delay," Entropy. An International and Interdisciplinary Journal of Entropy and Information Studies, vol. 18, no. 7, 2016.

[18] J. Ma and H. I. Bangura, "Complexity analysis research of financial and economic system under the condition of three parameters' change circumstances," Nonlinear Dynamics, vol. 70, no. 4, pp. 2313-2326, 2012.

[19] J. Ma, Y. Wang, and W. Xu, "Research on the triopoly dynamic game model based on different rationalities and its chaos control," WSEAS Transactions on Mathematics, vol. 13, pp. 983991, 2014. 


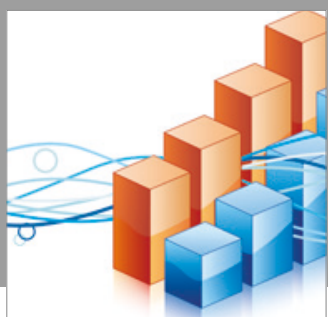

Advances in

Operations Research

vatersals

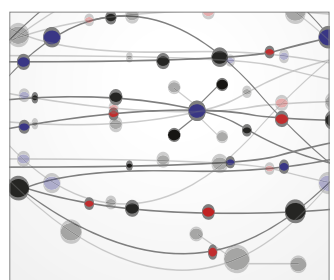

\section{The Scientific} World Journal
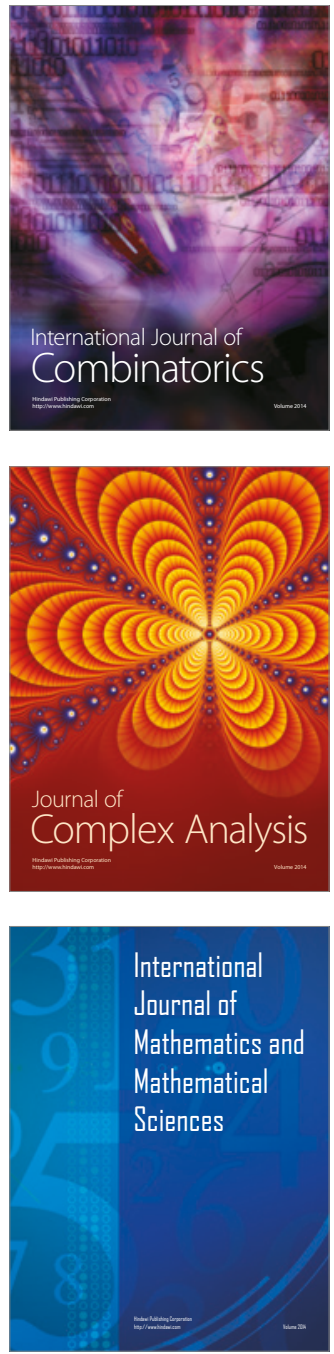
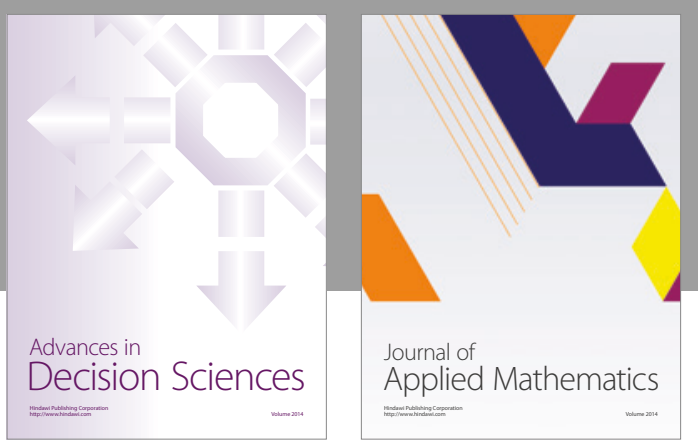

Algebra

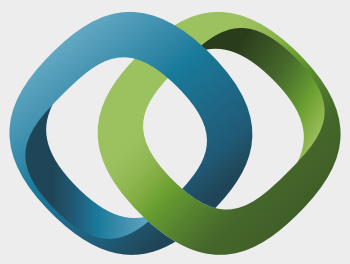

\section{Hindawi}

Submit your manuscripts at

https://www.hindawi.com
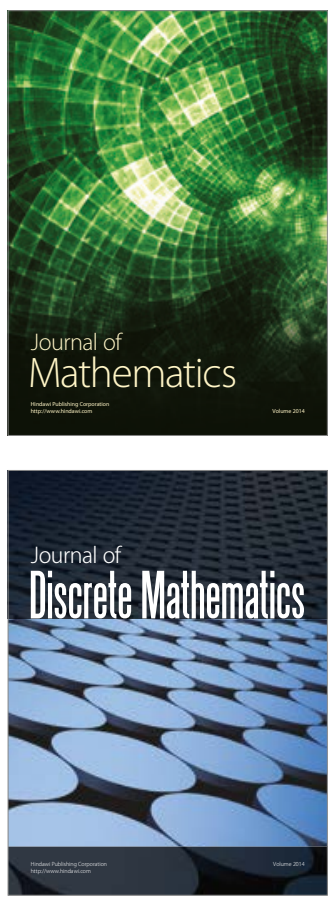

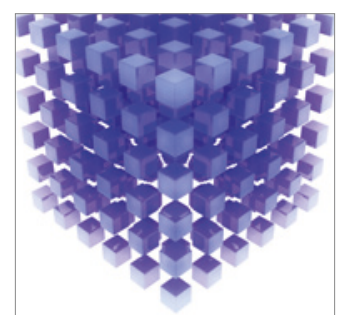

Mathematical Problems in Engineering
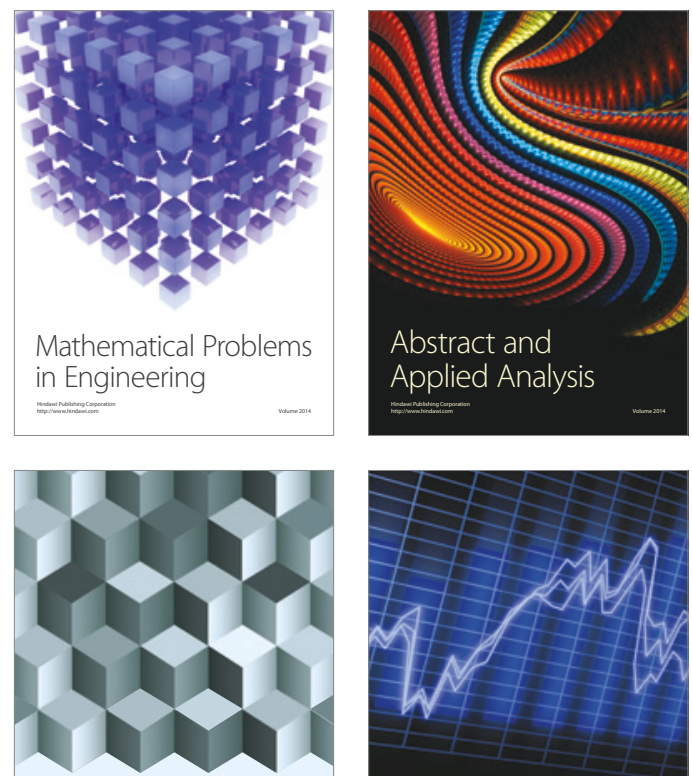

Journal of

Function Spaces

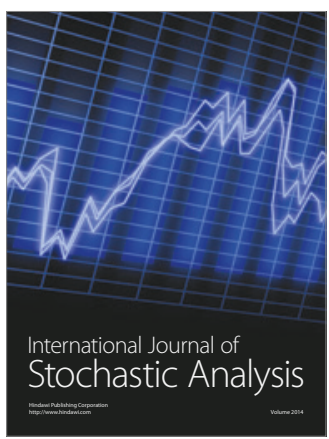

Probability and Statistics
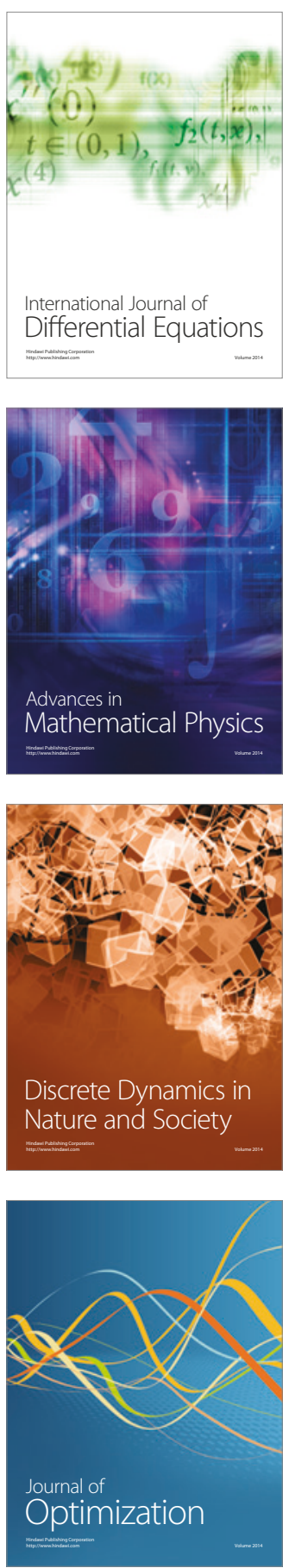